Article

\title{
Comparison of the Roles of Optimizing Root Distribution and the Water Uptake Function in Simulating Water and Heat Fluxes within a Maize Agroecosystem
}

\author{
Fu Cai ${ }^{1}$, Yushu Zhang ${ }^{1, *}$, Huiqing Ming ${ }^{2}$, Na Mi ${ }^{1}$, Shujie Zhang ${ }^{1}$, Hui Zhang ${ }^{3}$, Yanbing Xie ${ }^{1}$ \\ and Xianli Zhao ${ }^{1}$ \\ 1 Institute of Atmospheric Environment, China Meteorological Administration, Shenyang 110166, China; \\ caifu_80@163.com (F.C.); mina7921@126.com (N.M.); zhangshujie_a@163.com (S.Z.); \\ 13804217126@163.com (Y.X.); zhaoxianli2001@163.com (X.Z.) \\ 2 Liaoning Province Meteorological Service Center, Shenyang 110166, China; 15940037069@163.com \\ 3 Jinzhou Ecology and Agriculture Meteorological Center, Jinzhou 121001, China; zhanghui.107@163.com \\ * Correspondence: yushuzhang@126.com; Tel.: +86-024-8389-3250
}

Received: 20 May 2018; Accepted: 11 August 2018; Published: 17 August 2018

\begin{abstract}
Roots are an important water transport pathway between soil and plant. Root water uptake (RWU) plays a key role in water and heat exchange between plants and the atmosphere. Inaccurate RWU schemes in land surface models are one crucial reason for decreased model performance. Despite some types of RWU functions being adopted in land surface models, none have been certified as suitable for maize farmland ecosystems. Based on 2007-2009 data observed at the maize agroecosystem field station in Jinzhou, China, the RWU function and root distribution (RD) in the Common Land Model (CoLM) were optimized and the effects of the optimizations on model performance were compared. Results showed that RD parameters calculated with root length density were more practical relative to root biomass in reflecting soil water availability, and they improved the simulation accuracy for water and heat fluxes. The modified RWU function also played a significant role in optimizing the simulation of water and heat fluxes. Similarly, the respective and integrated roles of two optimization schemes in improving CoLM performance were significant during continuous non-precipitation days, especially during the key water requirement period of maize. Notably, the improvements were restrained within a threshold of soil water content, and the optimizations were inoperative outside this threshold. Thus, the optimized RWU function and the revised RD introduced into the CoLM model are applicable for simulation of water and heat fluxes for maize farmland ecosystems in arid areas.
\end{abstract}

Keywords: root water uptake; root length density; land surface model; water and heat flux; maize agroecosystem

\section{Introduction}

Roots are an important pathway for water and energy exchange between the soil, vegetation and the atmosphere [1]. The root water uptake (RWU) process as a key link in the surface water cycle, which distributes precipitation through evaporation, transpiration and infiltration, and closely connects with carbon cycle processes through coupling with photosynthesis [2]. Comprehensive research on RWU and its parameterization scheme will strengthen understanding of surface hydrology and land surface processes and help to improve the performance of land surface and climate models [3]. RWU schemes consist of two components: Root distribution (RD) and RWU efficiency. The former 
relates to the distribution of RWU at various soil depths [4,5], but available data are very scarce because of difficulties with observation, leading to simplifications of corresponding parameters thereby affecting simulation of the RWU process. There are three root distribution parameterization schemes in existing mainstream land surface models. The first one proposed by Jackson et al. [6] has an exponential relationship between accumulated root fraction and soil depth, as applied in the Land Surface Model from National Center for Atmo-spheric Research (NCAR LSM) [7], the Integrated Biosphere Simulator (IBIS) [8], theDynamic Global Vegetation Model (DGVM) [9] and Simple Biosphere (SiB) [10] models. The second one proposed by Zeng [11] is known as the double-parameter exponential scheme and was applied to the Community Land Model version 3 (CLM3) and version 4.5 models. The last one proposed by Schenk and Jackson [12] introduced two parameters, $d_{50}$ and $d_{95}$, referred to as the soil depths above which $50 \%$ and $95 \%$ of total roots are distributed, respectively; it also considered the accumulated root fraction and soil depth and was applied to the Common Land Model (CoLM) [13]. Comparison among the three schemes, using maize root biomass data, showed that the third scheme was superior [14]. Sensitivity analysis showed that simulation of water and heat fluxes between land and atmosphere in a maize agroecosystem was more sensitive to $d_{50}$ than to $d_{95}$ [15], which was verified for a desert shrub ecosystem of Central Asia [16]. Accumulated root fractions calculated with the above-mentioned methods were based on root biomass data. However, Schenk and Jackson [12] indicated that root biomass, root quantity or root length density can be used to calculate the accumulated root fraction, resulting in large differences in numerical values [14,17]. It is not known which data is best used for calculating the accumulated root fraction to ensure reliable simulation of land surface processes.

RWU efficiency, represented by the root water use efficiency function also referred to as the water stress function $[18,19]$, has been extensively investigated and developed by many scholars $[10,20,21]$. The transpiration weight model considers that RWU intensity linearly varies with the soil profile and is proportional to the transpiration rate, root density and soil water diffusivity. Based on this linear model, nonlinear models, e.g., Molz [22] and Chandra-Amaresh [23] models, also take hydraulic conductivity, potential transpiration, suction of roots and soil, and soil water suction into account, promoting the model mechanism. Moreover, the potential and actual evapotranspiration [18] as well as the effects of soil water content (SWC) and potential [19] were considered in the description of the RWU efficiency function, further improving RWU function. Even if some of the plant roots suffer water stress, the other roots can still absorb enough water to reach potential transpiration [24] Zheng and Wang [4] introduced accumulated root efficiency and the water availability threshold parameters to the RWU function and improved model simulation accuracy over forest ecosystems. Jing et al. [16] compared three RWU parameterization schemes proposed respectively by Lai and Katul [18], Li et al. [19], and Zheng and Wang [4] and verified that the third one indicated the greatest model performance in a desert ecosystem. In addition, a revised RWU function with an exponential relationship between soil water availability and SWC proposed by Li et al. [25] increased the CLM model's performance over a desert ecosystem in Central Asia. In consideration of the above conclusions, Cai et al. [26] compared the schemes of Li and of Zheng and Wang in raising performance of CoLM within a maize ecosystem and concluded that both increased simulation accuracy, but the latter was superior. Although the RWU scheme has been improved, existing mainstream land surface process models such as the CoLM, CLM3, the Community Atmosphere Biosphere Land Exchange (CABLE) [27] and SiB serial models [10] adopt only simple linear functions to express soil water availability, decreasing the accuracy of the RWU function and causing underestimation of evapotranspiration $[10,20,21]$. Research on RWU parameterization schemes largely involves underlying forest, wheat [4,19] and desert [16] surface types, and it is difficult to make a universal conclusion. Consequently, further verifications of more land surface types are required.

Among all plant types, maize is of significant representation in land surface process studies $[28,29]$ owing to its varying canopy and root structure causing changes in radiation and heat transfer, as well as water consumption processes, during the growing period [14]. Few studies on RWU parameterization 
for maize farmland ecosystems have been carried out, and more are required to determine whether schemes applicable to other underlying surfaces can be applild to maize farmland.

This study was conducted for three purposes:

(1) To investigate the effects of the root distribution parameter, i.e., $d_{50}$ and $d_{95}$ calculated with root biomass and root length density on simulating water and heat fluxes between an underlying maize farmland surface and the atmosphere;

(2) To compare improvements in performance of CoLM using optimized root distribution parameters and RWU schemes proposed by Zheng and Wang and their combined action;

(3) To investigate the applicability of the revised CoLM with optimized RWU schemes to a maize farmland ecosystem.

\section{Data and Methods}

\subsection{Site Description}

The data adopted in this research originate from the farmland ecosystem field station in Jinzhou, a research station in a typical rain-fed maize agroecosystem in Northeast China. The station $\left(41^{\circ} 49^{\prime} \mathrm{N}\right.$, $121^{\circ} 12^{\prime} \mathrm{E}, 17 \mathrm{~m}$ above sea level) is located in a representative temperate monsoon climate area with an annual mean temperature of $9.4^{\circ} \mathrm{C}$ and annual rainfall of $565.9 \mathrm{~mm}$ calculated using corresponding data from 1971-2000. Rain-fed maize as the dominant vegetation without any irrigation has a growing period from May-September. Data of latent and sensible heat fluxes were measured using a $3.5 \mathrm{~m}$ high eddy covariance observation system equipped with a three-dimensional sonic anemometer (CSAT3, Campbell Scientific Ltd., Logan, UT, USA) and a fast response infrared $\mathrm{CO}_{2} / \mathrm{H}_{2} \mathrm{O}$ analyzer (Li-7500, Li Cor Inc., Lincoln, NE, USA) Temperature, humidity and wind speed at $5 \mathrm{~m}$ height, as well as photosynthetically active radiation at $4.5 \mathrm{~m}$ height and net radiation at $3.5 \mathrm{~m}$ height were observed using a 5-m high gradient meteorological observation system [30].

\subsection{Meteorological Conditions}

Land surface model-driving data consisted of specific humidity, wind speed, air temperature, precipitation, solar radiation (Rs), downward longwave radiation (Rl), barometric pressure (Figure 1), leaf area index (LAI) and vegetation coverage fraction (VCF) data (Figure 2) during 2007-2009. The specific humidity data varied among different seasons: Low in winter with the value smaller than $0.005 \mathrm{~kg} \mathrm{~kg}^{-1}$, and high in summer with the maximum value about $0.02 \mathrm{~kg} \mathrm{~kg}^{-1}$. Daily maximum wind speed was in the range of 3-15 $\mathrm{m} \mathrm{s}^{-1}$, and was greatest in winter and lowest in summer. Daily average temperature indicated a clear yearly fluctuation with a low of $-33.2^{\circ} \mathrm{C}$ in winter and a high of $36.9^{\circ} \mathrm{C}$ in summer. Precipitation was largely distributed in summer and demonstrated large inter-annual variations. Growing-season precipitation was 454, 563 and $295 \mathrm{~mm}$ from 2007-2009, respectively, showing remarkably lower rainfall in 2009 . $\mathrm{Rl}$ varied within $170-460 \mathrm{~W} \mathrm{~m}^{-2}$ across the year, and Rs fluctuated within $800-1000 \mathrm{~W} \mathrm{~m}^{-2}$ during the growing season with a minimum of around $400 \mathrm{~W} \mathrm{~m}^{-2}$ in winter.

\subsection{LAI and VCF}

LAI and VCF as the key canopy parameters play an important role in water and energy exchanges over the underlying plant surface. Inaccurate simulation of LAI and VCF will directly decrease model performance [30] and so we used simulated day-to-day LAI data based on discontinuous observations. More specifically, daily LAI was calculated based on measured LAI at different maize growth periods and daily mean temperature data using the relative effective cumulative temperature method [26]. According to the relationship between LAI and VCF [31], daily LAI values were used to calculate day-to-day VCF values (Figure 2). LAI and VCF reached maxima of around $3.7 \mathrm{~m}^{2} \mathrm{~m}^{-2}$ and 1 for 2007 and 2008, respectively, and correspondingly $4.8 \mathrm{~m}^{2} \mathrm{~m}^{-2}$ and 1 for 2009, in the tasseling stage, and then declined gradually until the end of growing season (Figure 2). 


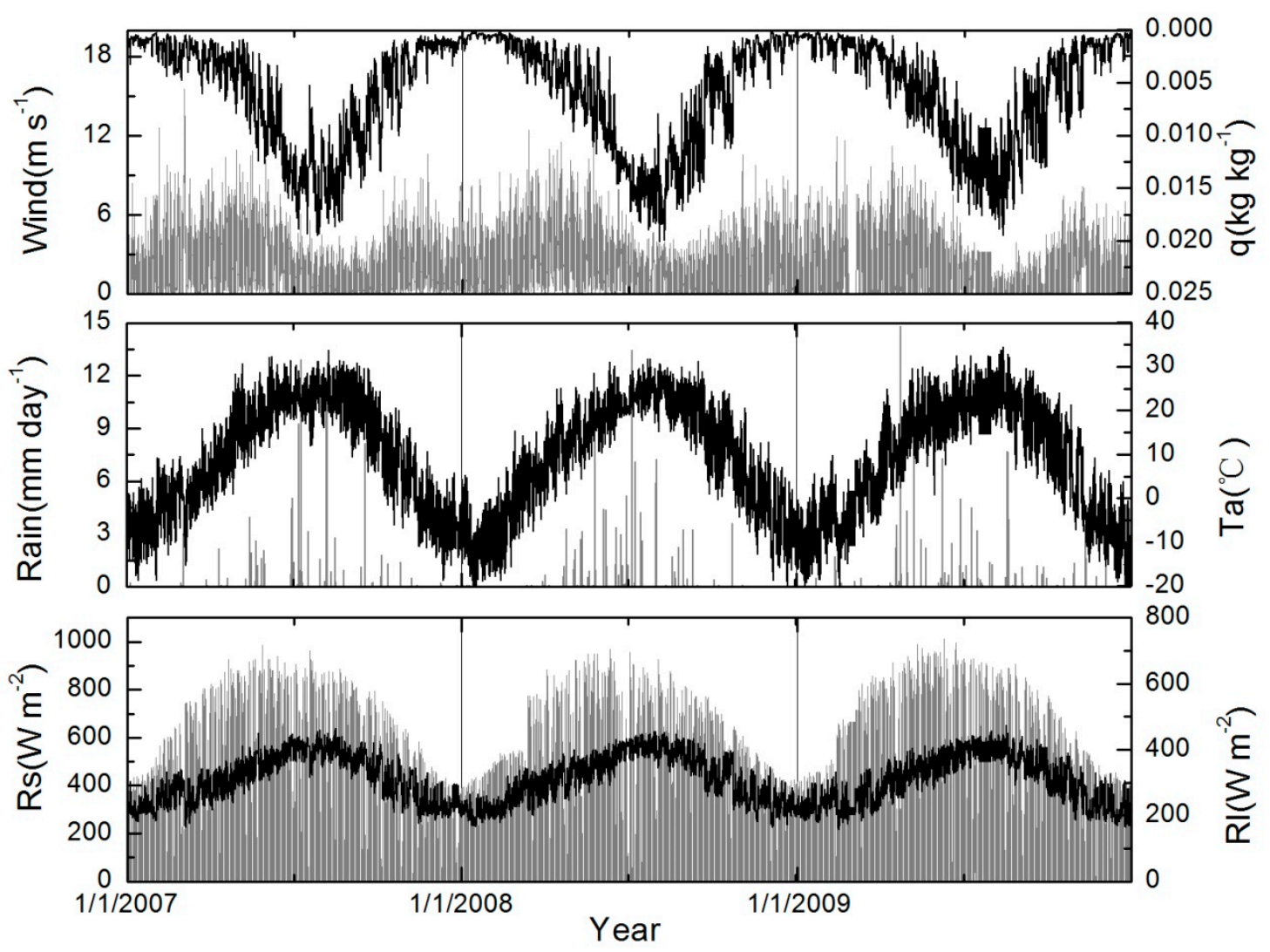

Figure 1. Half-hourly wind speed (Wind, gray) and specific humidity (q, black), air temperature (Ta, black), short wave radiation (Rs, gray) and long wave radiation (Rl, black) and daily precipitation (Rain, gray) at Jinzhou in Northeast China during 2007-2009.

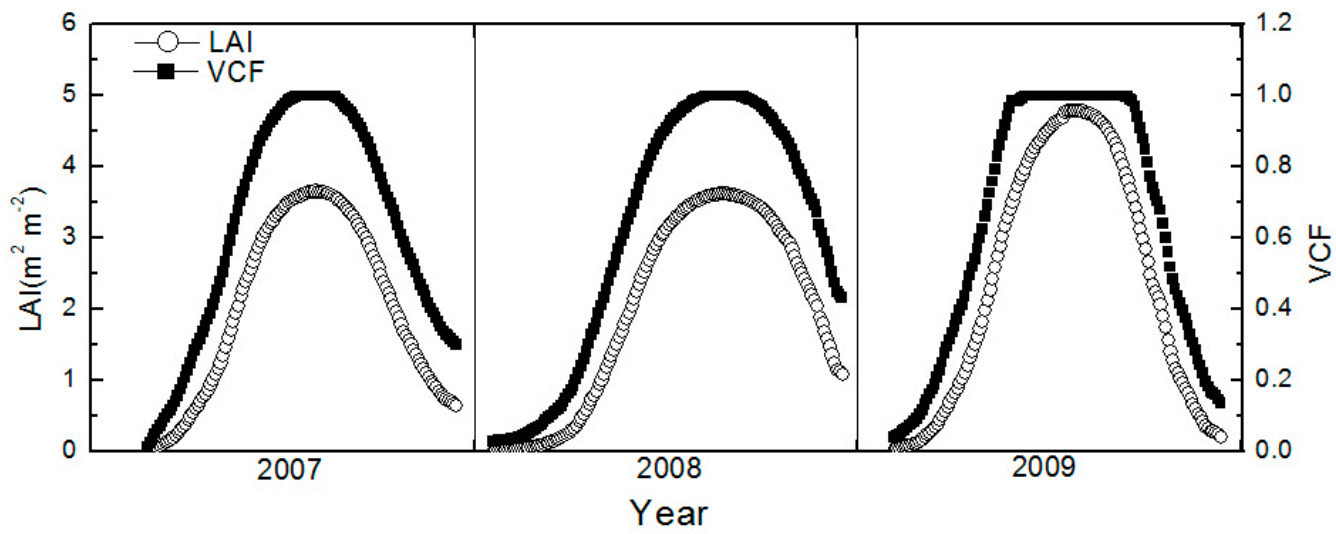

Figure 2. Dynamics of leaf area index (LAI) and vegetation cover fraction (VCF) during 2007-2009.

\subsection{Root Data}

Root biomass (RB) data, above a soil depth of $1.000 \mathrm{~m}$ with $0.100-\mathrm{m}$ intervals, used to calculate accumulated root fraction were obtained from research carried out by Guan et al. [32] and were measured at jointing (JT), bell mouth (BM), flare opening (FO), tasseling (TL), filling (FL) and mature (MT) stages of maize, i.e., the 26th, 48th, 57th, 66th, 78th, and 114th day after sowing, using a root drill mining method as part of a field experiment in the trial area of the Beijing Academy of Agriculture and Forestry Sciences in 2006. The root length density (RLD) data above a soil depth of $1.400 \mathrm{~m}$, with 0.20 -m intervals, were observed every 7 days using a mini-rhizotron method [33] as part of an 
experiment conducted at Jinzhou in 2012. The sowing date for the experiment was 30 April and the jointing and mature dates were on the 48th and 148th day after sowing, respectively.

The parameter $d_{95}$ increased with maize growth, whereas $d_{50}$ was almost invariable after the jointing stage (Figure 3a); their averages were 0.633 and $0.158 \mathrm{~m}$, respectively. Conversely, $d_{50}$ dramatically fluctuated, with an average of $0.437 \mathrm{~m}$, during the maize growth season, and $\mathrm{d}_{95}$ slightly varied with a mean of $1.310 \mathrm{~m}$ (Figure $3 \mathrm{~b}$ ). The parameters $d_{50}$ and $d_{95}$ calculated using the RB and RLD data were clearly larger than the default values of 0.157 and $0.808 \mathrm{~m}$ in the CoLM, respectively.

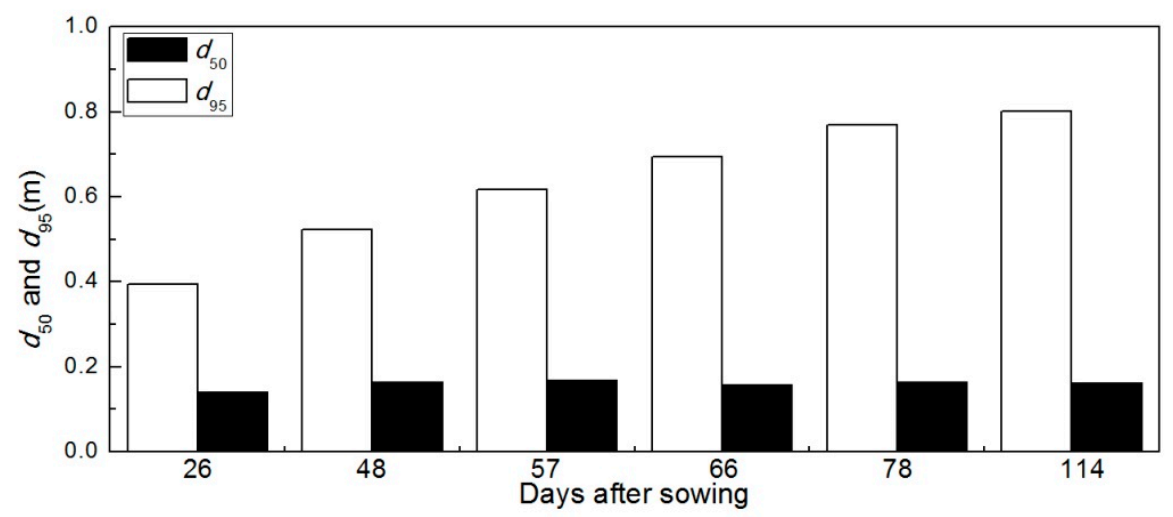

(a)

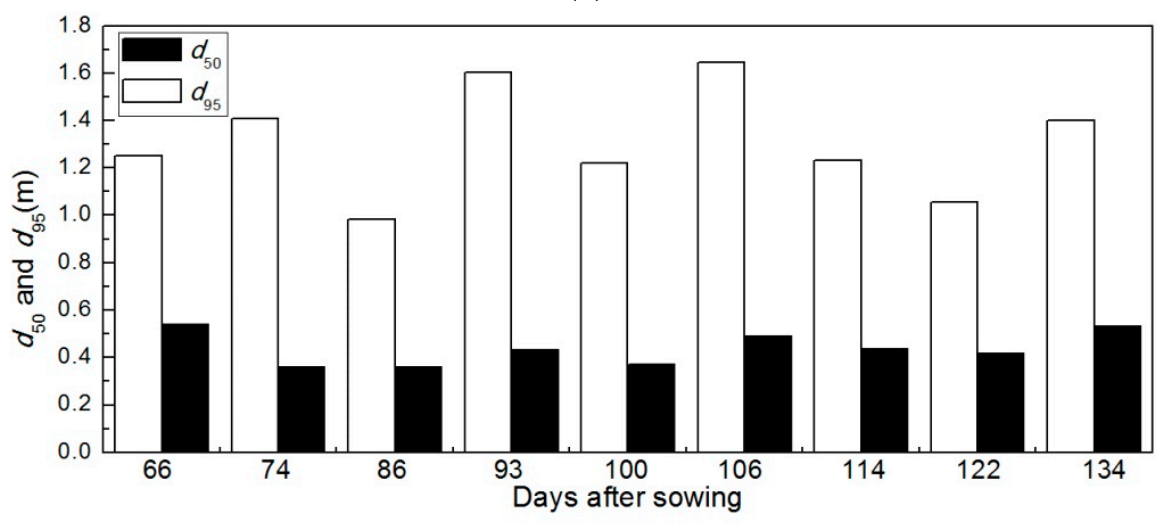

(b)

Figure 3. The root distribution parameters $d_{50}$ (black) and $d_{95}$ (white) calculated with root biomass data measured in 2006 (a) and root length density data measured in 2012 (b).

\subsection{Validation Data}

Model validation data consisted of 0-50 cm SWC measured with the soil auger method every 5 days, and the 30-min average sensible and latent heat fluxes under high-frequency attenuation correction and hydrothermal correction, aiming at removing the effect of humidity on measuring air temperature fluctuation. As a result of deficiency of partial latent heat flux data accounting for about 20 percent of total data in the growth season in 2009, a look-up table method was used to fill the missing data [34]. For the look-up table method, the tables were created for the research site based on the environmental conditions associated with the flux data therefore the missing data could be "look-up" according to similar environmental condition.

\subsection{Model Description}

This research used the CoLM land surface model [13], in which ecological and hydrological processes were considered in detail and water and energy transmission among soil, vegetation and atmosphere were reasonably described. The model consisted of a layer of vegetation capable of 
conducting photosynthesis and 10 vertical soil layers with layer depths of $0.018,0.045,0.091,0.166$, $0.289,0.493,0.829,1.383,2.296$ and $3.433 \mathrm{~m}$. Soil bedrock thickness, surface runoff, subsurface runoff and the effect of root distribution and water pressure on water uptake were taken into consideration for water and heat transmission processes of soil. Root distribution adopted the scheme proposed by Schenk and Jackson [12]. All model parameters and variables are listed in Table 1.

Table 1. Parameters and variables used in this paper.

\begin{tabular}{|c|c|c|c|}
\hline Symbol & Description & Value & Unit \\
\hline$\theta$ & Volumetric of soil water content (SWC) & & $\mathrm{m}^{3} \mathrm{~m}^{-3}$ \\
\hline$z$ & Soil depth & $0-3.43$ & $\mathrm{~m}$ \\
\hline$E_{x}$ & Water extraction & & $\mathrm{m}^{3} \mathrm{~m}^{-3} \mathrm{~s}^{-1}$ \\
\hline$T$ & Actual transpiration & & $\mathrm{mm} \mathrm{s}^{-1}$ \\
\hline$W_{\mathrm{t}}$ & The accumulates root resistance factor & $0-1$ & \\
\hline$D$ & soil moisture diffusivity & & $\mathrm{mm}^{2} \mathrm{~s}^{-1}$ \\
\hline K & hydraulic conductivity & & $\mathrm{mm} \mathrm{s}^{-1}$ \\
\hline$T_{p o t}$ & potential transpiration & & $\mathrm{mm} \mathrm{s}^{-1}$ \\
\hline$\eta_{i}$ & Soil water availability within layer $i$ & $0-1$ & - \\
\hline$f_{\text {root }, i}$ & Root fraction within soil layer $i$ & $0-1$ & \\
\hline$f_{s w, i}$ & Soil water availability & $0-1$ & \\
\hline$f_{s w, \max }$ & Soil water availability factor in the wettest layer of the root zone & $0-1$ & \\
\hline$c$ & A dimensionless shape-parameter & & \\
\hline$i$ & Soil layer & $1-10$ & \\
\hline$d_{50}$ & The depth above which $50 \%$ of all roots were located & 0.157 & $\mathrm{~m}$ \\
\hline$d_{95}$ & The depth above which $95 \%$ of all roots were located & 0.808 & $\mathrm{~m}$ \\
\hline$\varphi_{\max }$ & Soil water potential at wilting point within soil layer $i$ & $-1.5 \times 10^{5}$ & $\mathrm{~mm}$ \\
\hline$\varphi_{\text {sat }}$ & Saturated soil water potential & & $\mathrm{mm}$ \\
\hline$\varphi_{i}$ & Soil water potential & & $\mathrm{mm}$ \\
\hline$W_{t, a d j u s t e d}$ & Redefined $W_{t}$ & $0-1$ & \\
\hline$W_{\mathrm{c}}$ & A threshold used in RWUFZ & & \\
\hline$W_{\mathrm{x}}$ & A threshold used in RWUFZ & & \\
\hline$k$ & A tunable parameter used in RWUFZ & 4 & \\
\hline$\alpha(i)$ & A variable to determine the water uptake allocation & $0-1$ & \\
\hline
\end{tabular}

\subsubsection{Default RWU Parameterization Scheme for the Model}

Water movement in soil is calculated using Darcy's law in CoLM using the following equation:

$$
\frac{\partial \theta}{\partial t}=-\frac{\partial}{\partial z}\left(K-D \frac{\partial \theta}{\partial Z}\right)-E_{x}
$$

where, $K$ and $D$ represent SWC $\left(\mathrm{m}^{3} \mathrm{~m}^{-3}\right)$, hydraulic conductivity $\left(\mathrm{mm} \mathrm{s}^{-1}\right)$ and soil moisture diffusivity $\left(\mathrm{mm}^{2} \mathrm{~s}^{-1}\right)$, respectively; $z$ is the soil depth $(\mathrm{m})$ and $t$ is the time (s). The sink term $E_{x}\left(\mathrm{~m}^{3} \mathrm{~m}^{-3} \mathrm{~s}^{-1}\right)$ is referred to as the volume of root water extraction from unit volume soil in unit time.

Total transpiration $(T)$ is distributed to each soil layer $(i)$ by a proportion factor $\eta_{i}$ :

$$
\begin{gathered}
E_{x}=T \eta_{i} /\left(z_{i}-z_{i-1}\right) \\
T=W_{t} \times T_{p o t}
\end{gathered}
$$

where $z_{i}-z_{i-1}$ stands out the thickness of the $i$ th layer, $T_{\text {pot }}$ represents potential plant transpiration, and $W_{t}$ is the accumulated root efficiency factor.

$$
\begin{gathered}
W_{t}=\sum_{i=1}^{n} f_{r o o t, i} f_{s w, i} \\
\eta_{i}=\frac{f_{r o o t, i} f_{s w, i}}{W_{t}}
\end{gathered}
$$


where $f_{\text {root }, i}$ is the root fraction within soil layer $i$, written as:

$$
f_{\text {root }, i}=\frac{1}{1+\left(\frac{z}{d_{50}}\right)^{c}}
$$

where $c$ is a dimensionless root profile parameter, calculated as:

$$
c=\frac{-1.27875}{\lg d_{95}-\lg d_{50}}
$$

where $d_{50}$ and $d_{95}$ represent soil depths with $f_{\text {root }, i}=50 \%$ and $f_{\text {root }, i}=95 \%$, respectively.

The $f_{s w, i}$ represents the soil water availability of the $i$ th layer, which shows a linear relationship with the soil matric potential in CoLM:

$$
f_{s w, i}=\frac{\varphi_{\max }-\varphi_{i}}{\varphi_{\max }+\varphi_{\text {sat }}}
$$

where $\varphi_{\max }, \varphi_{\text {sat }}$ and $\varphi_{i}$ represent soil water potential at the wilting point and saturated and actual SWC, respectively.

\subsubsection{Optimization Method of RWU Function}

An empirical nonlinear RWU function proposed by Zheng and Wang [4] introduced two threshold parameters to represent the dynamic root water uptake capability. The accumulated root efficiency $W_{t}$ in the CoLM model used to calculate the root efficiency at each soil layer was redesigned as:

$$
W_{t, a d j u s t e d}=\left\{\begin{array}{l}
1.0, W_{t} \geq W_{c} \\
\frac{W_{t}}{W_{c}}, W_{t}<W_{c}
\end{array}\right.
$$

where $W_{c}$ is an adjustable threshold value in the range of 0.0-1.0. This function suggests that for $W_{t} \geq W_{c}$, the plants would be able to attain potential transpiration despite part of the root experiencing water stress. $T_{\text {pot }} \times W_{t, a d j u s t e d}$ is used to reflect the total RWU. So, to describe RWU distribution, a water uptake variable $\alpha(i)$ is defined as:

$$
\alpha(i)=\left\{\begin{array}{l}
0.0, f_{s w, i}<\min \left(f_{s w, \max }, W_{x}\right) \\
1.0, f_{s w, i} \geq \min \left(f_{s w, \max }, W_{x}\right)
\end{array}\right.
$$

$f_{s w, \max }$ represents the water availability of the wettest soil layer and $W_{x}$ is the water availability threshold. Equation (10) shows that when the water availability in a certain soil layer is lower than $W_{x}$, then no water is absorbed by the roots unless the layer is the wettest among the whole root zone. The sensitivity analysis of Cai et al. [26] indicated that, for the maize farmland ecosystem, the variation of $W_{x}$ below a value of 0.4 did not impact on model simulation results but model performance was sensitive to $W_{c}$ and decreased with an increase of $W_{c}$ based on a reasonable initial value of 0.4. As a result, we assigned both $W_{c}$ and $W_{x}$ the value of 0.4 in this study.

$\eta_{i}$ in Equation (5) in the default model is redefined as:

$$
\eta_{i}=\frac{f_{\text {root }}(i) f_{s w, i}^{k} \alpha(i)}{\sum_{i=1}^{n} f_{\text {root }}(i) f_{s w, i}^{k} \alpha(i)}
$$

where for adjustable parameter $k>1.0$ indicates a nonlinear relationship between water availability and water uptake and enables a higher percentage of water to be absorbed by roots in relatively wet soil layers. Zheng and Wang [4] assigned a suitable $k$ value of 4 and argued that the increase in $k$ had little effect on model performance, and so we used $k=4$ in this study. 


\subsubsection{Model Simulation Schemes}

Two types of data associated with roots, RB and RLD, were used to calculate root distribution parameters for determining optimal root data in simulating water and heat fluxes over a maize agroecosystem based on the CoLM.

As root distribution parameters calculated with RB were almost same as the CoLM default values, we regarded the default root distribution parameter as that calculated with $R B$, and the corresponding simulation adopting the default RWU function was defined as M0. In turn, we defined the root distribution parameter calculated with RLD as the optimized root distribution scheme, and the corresponding simulation with the default RWU function was defined as M1. Vertical distribution profiles of accumulated root fraction calculated with Equation (6) based on the default and optimized root distribution parameters were applied in M0 and M1 (Figure 4).

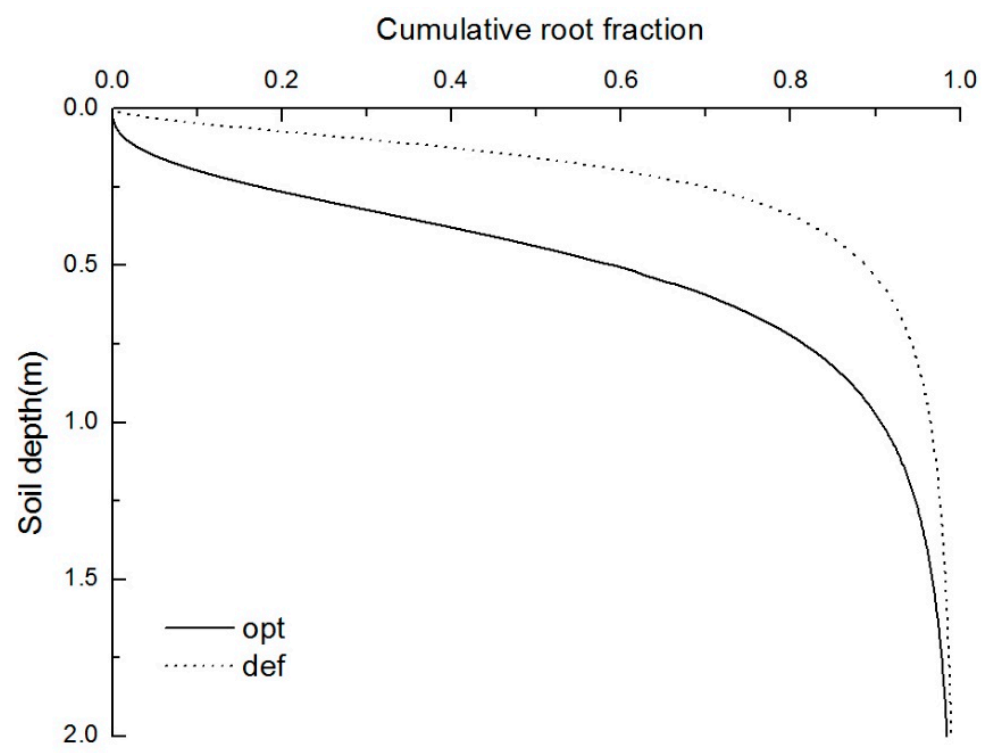

Figure 4. Vertical distribution profiles of accumulated root fraction based on the default (def) and optimized (opt) root distribution parameters.

The simulation with the optimized RWU function, but without the optimized root distribution scheme, was defined as M2. The simulation simultaneously integrating the optimized root distribution scheme and the optimized RWU function was defined as M3.

\subsection{Statistical Analysis}

Linear correlation coefficients $(R)$, root mean square errors (RMSE) and Nash-Sutcliffe (NS) [35] were used to quantitatively evaluate the agreement between simulations and observations. An efficiency of 1 (NS =1) corresponds to a perfect match of modeled discharge to the observed data. An efficiency of $0(\mathrm{NS}=0)$ indicates that the model predictions are as accurate as the mean of the observed data, whereas an efficiency less than zero (NS $<0$ ) occurs when the observed mean is a better predictor than the model. Their equations can be written as:

$$
\begin{gathered}
R=\frac{\sum_{i=1}^{n}\left(o_{i}-\bar{o}\right)\left(p_{i}-\bar{p}\right)}{\sqrt{\sum_{i=1}^{n}\left(o_{i}-\bar{o}\right)^{2} \sum_{i=1}^{n}\left(p_{i}-\bar{p}\right)^{2}}}, \\
\text { RMSE }=\sqrt{\frac{\sum_{i=1}^{n}\left(p_{i}-o_{i}\right)^{2}}{n}},
\end{gathered}
$$




$$
\mathrm{NS}=1-\frac{\sum_{i=1}^{n}\left(p_{i}-o_{i}\right)^{2}}{\sum_{i=1}^{n}\left(o_{i}-\bar{o}\right)^{2}}
$$

where $\bar{o}$ and $\bar{p}$ represent averages of the observations and simulations, respectively; $o_{i}$ and $p_{i}$ are the observed and simulated values at time-step $i$, respectively.

\section{Results}

\subsection{Effects of Optimized RWU Schemes on SWC at Different Depths}

According to the partitioning of soil layers in the CoLM, the thickness of the third soil layer in the model corresponded to a SWC observation depth of $0-10 \mathrm{~cm}$, represented as SWC10; the fifth layer was a depth of 20-30 cm, represented as SWC20-30; and the sixth layer was a depth of 30-50 $\mathrm{cm}$, represented as SWC30-50. Because soil moisture was usually measured during 09:00-10:00, the simulated soil moisture during the corresponding period was compared with actual observations.

SWC10 and SWC20-30 were underestimated to various extents by the simulation for the 2007 and 2008 growing seasons, compared with observed values (Figure 5). The errors were smaller on days with high-intensity precipitation, larger on precipitation-free days and increased with prolonged rain-free time. The observed SWC values were little influenced by small amounts of rain, possibly because the penetration of drizzle could not reach a depth of $10 \mathrm{~cm}$. Conversely, the simulated SWC values were more sensitive to light rain, which was against the above fact and might have been a key factor contributing to the errors in simulating SWC. Besides, an inaccurate parameterization scheme for the interception of the canopy during a rainy event in the model may also be the cause of error. The cases of SWC10 and SWC20-30 differed in 2009, compared with 2007 and 2008; the simulation errors caused by the underestimation were small.

More specifically, compared with M0, three optimization schemes (M1-M3) improved the simulation accuracy of SWC10 to varying degrees, especially during the rain-free period in the middle of the growing season. The maximum differences of the simulation error for SWC between M0 and M1, M2, M3 were $0.033,0.016$ and $0.038 \mathrm{~m}^{3} \mathrm{~m}^{-3}$ for 2007; $0.026,0.014$ and $0.030 \mathrm{~m}^{3} \mathrm{~m}^{-3}$ for 2008 as well as $0.045,0.031$, and $0.059 \mathrm{~m}^{3} \mathrm{~m}^{-3}$ for 2009 , implying that the improvements of simulation accuracy were more significant in 2007 and 2009 than in 2008. In contrast, there were no marked changes in simulation accuracy after the optimization for the earlier part of the growing season. The improvement was much smaller in M2 than in M1 and was somewhat larger in M3 than in M1 based on the proximity of the simulated and observed SWC. Generally, for SWC20-30, the improvements for all schemes were smaller relative to SWC10; the improvement was larger in M2 than in M1 and larger in 2007 and 2009 than in 2008. However, all four simulations significantly overestimated SWC30-50 for 2007 and 2009 and better reproduced values for 2008. The M2 simulation was closer to the measured values during the rain-free period in 2007 and 2009.

The above results indicated that the modified root distribution played a more important role in improving the simulation of SWC10 and SWC30-50 relative to the modified RWU function, but the latter better simulated SWC20-30 than the former. The improved simulations of SWC, the simulated SWCs increasing at the depth of $10 \mathrm{~cm}$ and declining at $30-50 \mathrm{~cm}$, were attributed to the decreased and increased uptake of soil water by roots at the corresponding depths, which was caused by the increase in parameter $d_{50}$ from 15.7 to $43.7 \mathrm{~cm}$ for the deeper main root zone. The role of the optimized RWU function was reflected in two respects during the continuous rain-free period in July-August when maize experienced the critical stage of demand for water, whereas RWU was greatly limited by long-term deficiency of precipitation. On the one hand, the optimized model generated larger simulated SWC values for this period with increased accuracy. On the other hand, the optimized model had lower accuracy for SWC simulation during the continuous non-precipitation periods in 2007 and 2008, possibly due to higher soil water availability than in 2009. Thus, the optimized model best performed only for soil moisture below a certain threshold. The effect of integrating the optimized RWU function and root distribution scheme on simulation of SWC was not equal to the sum of effects 
generated by the two optimizations (Figure 5), which means that the role played by a single factor might be reduced or offset significantly by the introduction of the other factor.

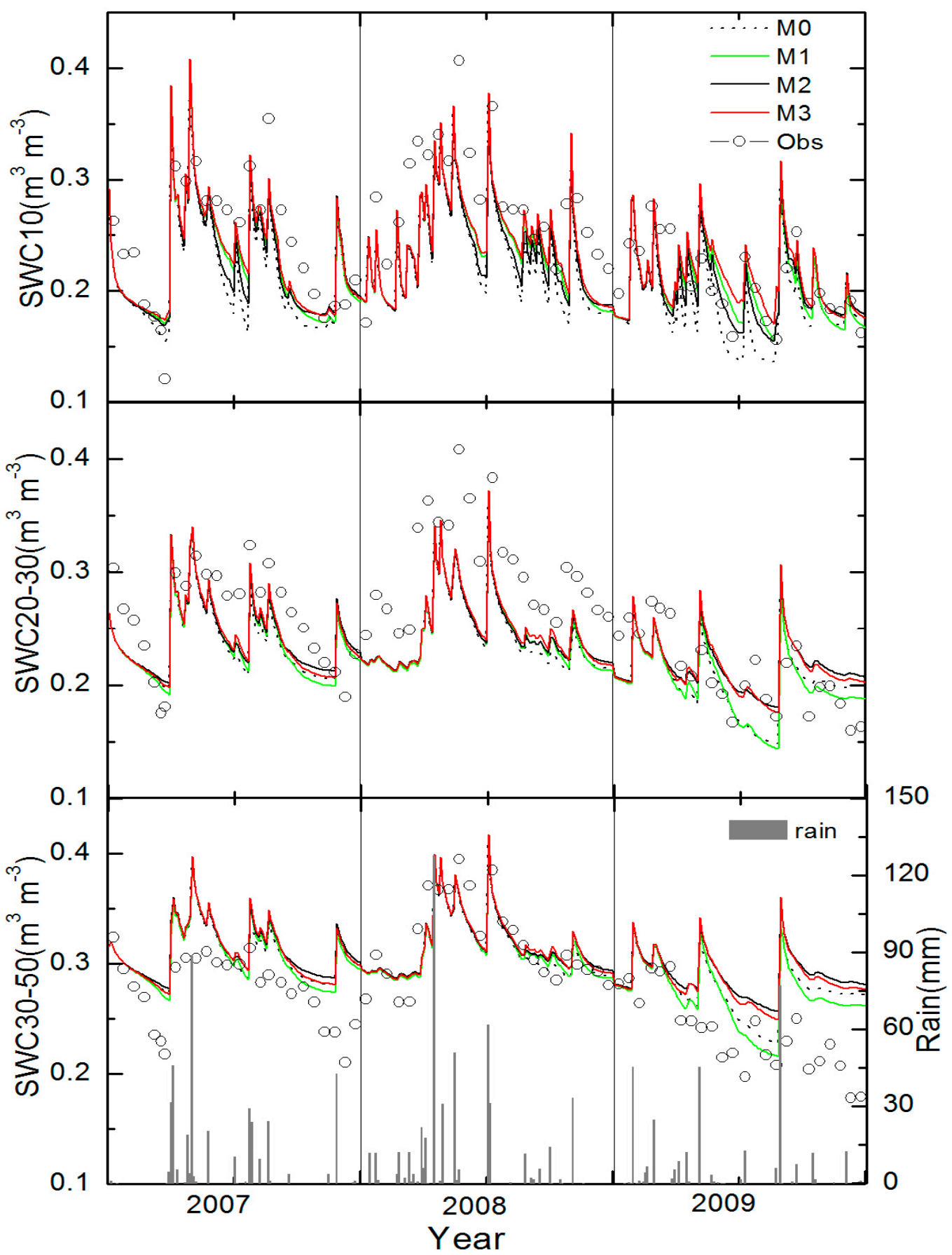

Figure 5. Comparison between the observed and the daily simulated SWC at different depths- $10 \mathrm{~cm}$ (SWC10), 20-30 cm (SWC20-30), and 30-50 cm (SWC30-50) based on the CoLM model with four schemes, M0-M3, during the 2007-2009 growing seasons (June-September). The grey column indicates daily precipitation during the growing seasons in 2007-2009.

In addition, the vertical distributions of monthly mean simulated SWCs for the 10 soil layers in the model for July-September during 2007-2009 were compared among different simulations. For the simulation using the default RWU scheme, there were clear differences in the vertical distributions of SWC both among different months in similar years and among different years for similar months 
(Figure 6). Specifically, the SWCs in 2007 were largest in July, followed by August and then September above the fifth layer, and increased sharply to varying extents from the fifth to sixth layer in every month because where main root zone was distributed. They decreased, increased slightly and greatly increased with deeper soil layers in July, August and September, respectively. During 2008, the vertical distribution patterns for SWC in different months were reasonably consistent with those in 2007, with SWCs at different depths slightly larger than those of 2007 for some months. In 2009, the simulated SWCs for various soil layers in the three months were all remarkably smaller than in 2007 and 2008, especially above the fifth layer. These differences in monthly mean SWCs among years were due to variation among corresponding monthly total precipitation (Figure 1).
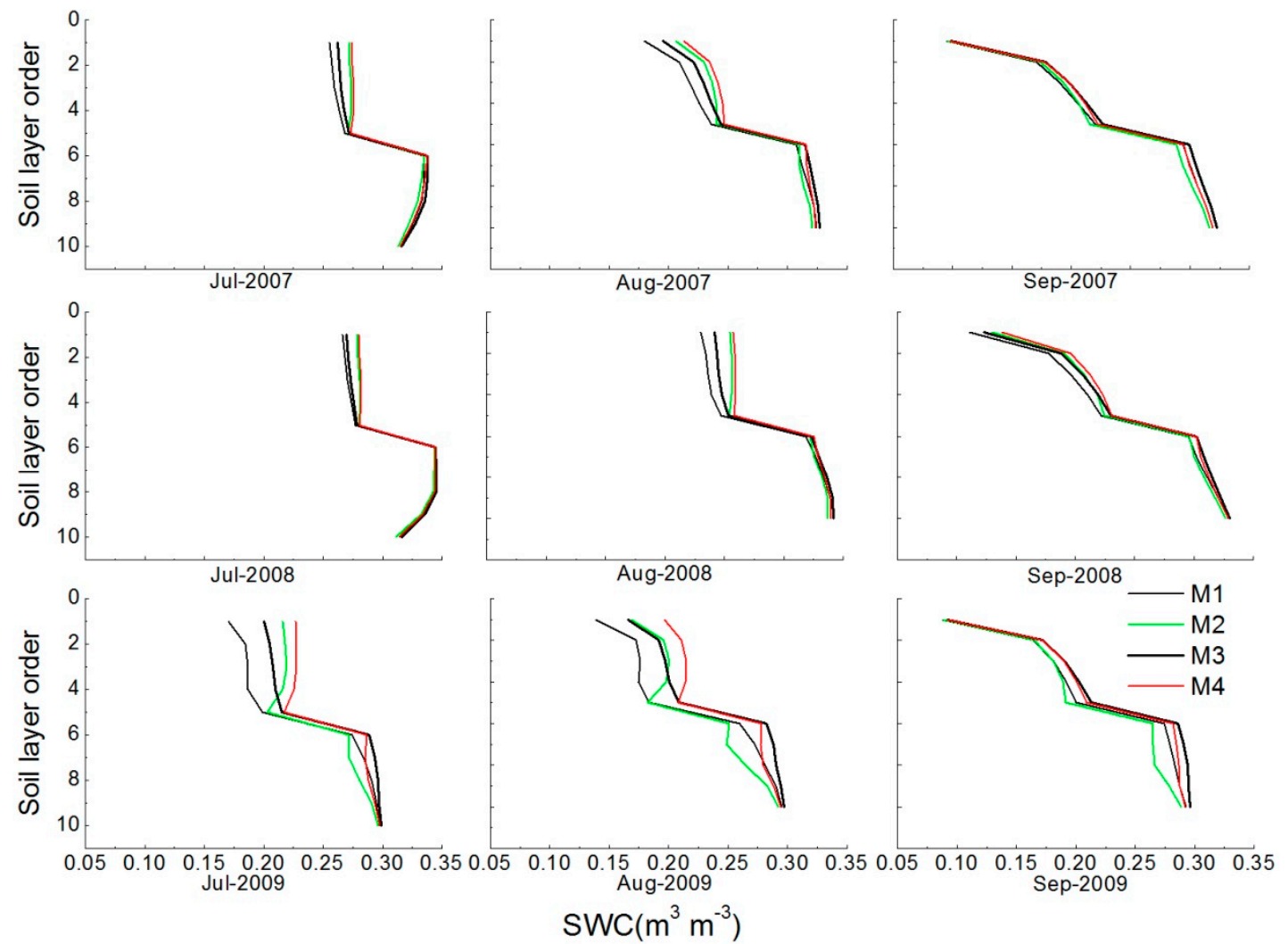
$\operatorname{SWC}\left(\mathrm{m}^{3} \mathrm{~m}^{-3}\right)$

Figure 6. Comparison of the vertical variation in monthly mean simulated soil water content (SWC) values based on the different RWU schemes in July (7), August (8) and September (9) during 2007-2009.

Large differences in effects of different RWU schemes on simulated SWCs were evident between the M0 and M1 simulations. Specifically, based on the optimized root distribution scheme, the simulated SWCs above the fifth layer increased significantly with decreasing soil depth in July and August and slightly increased in September; however, those below the sixth layer decreased slightly compared with the default simulations in 2007 and 2008. The variations in SWC for the top five layers in July and August and for the bottom layers in the three months were larger in 2007 than in 2008, and only in the top five layers in September were variations larger in 2008 than in 2007. The impact of the optimized root distribution scheme on the SWC distribution in 2009 clearly differed from the other years, where the changes in all layers relative to the default simulation were larger than in 2007 and 2008.

The simulated SWCs with the optimized RWU function increased to varying degrees at different depth. The magnitudes of the increases for the top five layers were larger than those below the sixth layer, and in the following order August > July > September. Additionally, the magnitudes were in the order $2009>2007>2008$. In conclusion, the role of optimized root distribution in increasing SWCs 
for the top five layers was larger than that of optimized RWU function in every month of 2007 and 2008, as well as in July 2009; but was very similar to and less than that of the latter in August and September, respectively.

Considering simultaneously the optimization of root distribution and RWU function, the most obvious superposition effect in increasing SWCs above the fifth layer was in July and August 2009, but correspondingly was not evident in 2007 and 2008. Conversely, the offset effects in varying SWCs below the sixth layer, from strong to weak, were in the order $2009>2007>2008$.

\subsection{Effects of Optimized Root Distribution and RWU Function on Latent and Sensible Heat Flux Simulation}

The simulated and observed diurnal patterns of 30-min latent and sensible heat fluxes from June to September were averaged under a monthly scale. The calculated diurnal patterns were compared to indicate more intuitively the model's performance of different optimization schemes. The default simulation gave high accuracy for both latent and sensible heat fluxes in 2008 (Figure 7), with simulated values almost identical to observed values of latent heat for July-August, and of sensible heat for June-August. In 2007, the simulated July and August latent heat and July sensible heat values also fitted the observed daily pattern well; nevertheless, substantial errors in both variables were apparent in June and September. In 2009, latent heat fluxes for July-September were underestimated to different extents, especially in August-September; whereas, sensible heat fluxes for June-August were markedly overestimated by different amounts. The optimized model increased the latent and sensible heat simulation accuracy slightly for 2007, little for 2008, and most obviously for 2009; this was demonstrated by the simulated July and August latent heat fluxes amplifying significantly to reduce underestimation of the default simulation, and the simulated July and August sensible heat values declining dramatically and remaining close to observed values. The modified RWU function played a more crucial role in improving simulation accuracies for latent and sensible heat fluxes relative to the optimized root distribution scheme.

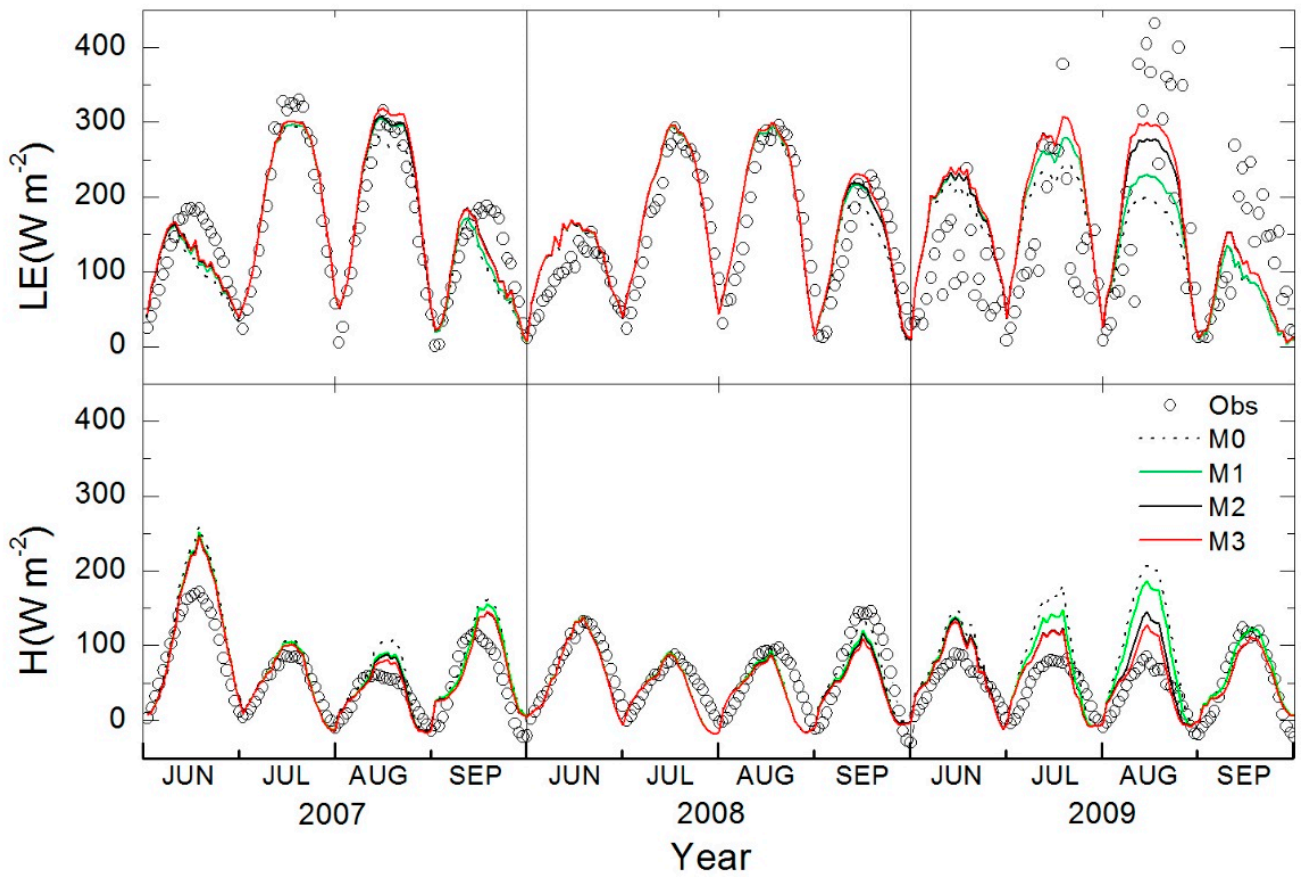

Figure 7. Comparison of simulated and observed values of diurnal variation for monthly averaged latent and sensible heat fluxes from June to September among different optimization schemes during 2007-2009. 
Although the gap-filled latent heat flux data for 2009 might not reflect actual conditions, the accurate reproduction of sensible heat fluxes compared with observations might well demonstrate the improving roles of the optimized RWU schemes on heat flux simulation.

The $R$, RMSE and NS values were used to more quantitatively indicate the effects of different optimization schemes on model performance in simulating the latent and sensible heat fluxes (Table 2). For simulation accuracy of both latent and sensible heat data, the maximum RMSE and minimum $R$ and NS values were both in 2009, and the minimum RMSE and maximum $R$ and NS values were in 2008. The RMSE, $R$ and NS values in 2007 fell in the middle, suggesting that model performance varied with year and that the simulation accuracies of both variables were highest in 2008, followed by 2007 and then 2009. Comparing the statistics among several simulations indicated that accuracies for all variables increased slightly in 2008, and remarkably in 2007 and 2009. More specifically, $R$ and NS for latent heat flux given by three simulations M1-M3 were all larger than those given by M0 for 2007-2009. RMSE decreased from $82.0 \mathrm{~W} \mathrm{~m}^{-2}$ in $\mathrm{M} 0$ to 79.4, 78.8 and $79.0 \mathrm{~W} \mathrm{~m}^{-2}$ for the M1-M3 in 2007 and from 82.1 in $\mathrm{M} 0$ to $81.1-81.7 \mathrm{~W} \mathrm{~m}^{-2}$ in 2008. There were larger reductions for RMSE in 2009, from $145.5 \mathrm{~W} \mathrm{~m}^{-2}$ in $\mathrm{M} 0$ to 138.0, 138.0 and $136.6 \mathrm{~W} \mathrm{~m}^{-2}$ for M1-M3, respectively. As for sensible heat flux, $R$ and NS values increased from M0 to M3 for 2007 and 2009 and decreased slightly for 2008. The improved simulation accuracies were reflected more significantly by decreasing RMSE, i.e., from $57.6 \mathrm{~W} \mathrm{~m}^{-2}$ in $\mathrm{M} 0$ to $49.6-52.1 \mathrm{~W} \mathrm{~m}^{-2}$ in M1-M3 for 2007, and for 2009 with 87.0 in M0 to 77.5, 68.4 and $64.8 \mathrm{~W} \mathrm{~m}^{-2}$ in M1-M3. Using combined data from the three years, $R$ and NS values for latent heat flux increased from 0.35 to $0.39-0.42$ and 0.14 to $0.18-0.19$ for M0-M3, respectively; and correspondingly the increases were also shown for sensible heat flux. The RMSEs of latent and sensible heat flux for M1-M3 decreased relative to M0, respectively.

Table 2. Comparison of the latent (LE) and sensible (H) heat flux simulation accuracies among different optimized RWU parameterization schemes.

\begin{tabular}{cccccccccc}
\hline \multirow{2}{*}{ Time } & Statistics & M0 & M1 & M2 & M3 & M0 & M1 & M2 & M3 \\
\cline { 3 - 10 } & & \multicolumn{3}{c}{ H } \\
\hline \multirow{2}{*}{2007} & $R$ & 0.63 & 0.66 & 0.64 & 0.66 & 0.77 & 0.79 & 0.80 & 0.80 \\
& RMSE & 57.6 & 52.1 & 50.9 & 49.6 & 82.0 & 79.4 & 78.8 & 79.0 \\
& NS & 0.02 & 0.20 & 0.24 & 0.27 & 0.46 & 0.51 & 0.52 & 0.52 \\
\hline \multirow{2}{*}{2008} & $R$ & 0.76 & 0.75 & 0.74 & 0.74 & 0.76 & 0.77 & 0.77 & 0.77 \\
& RMSE & 47.3 & 47.3 & 46.8 & 47.3 & 82.1 & 81.1 & 81.7 & 81.7 \\
& NS & 0.43 & 0.40 & 0.40 & 0.38 & 0.48 & 0.49 & 0.48 & 0.48 \\
\hline \multirow{2}{*}{2009} & $R$ & 0.50 & 0.50 & 0.50 & 0.52 & 0.25 & 0.32 & 0.38 & 0.40 \\
& RMSE & 87.0 & 77.5 & 68.4 & 64.8 & 145.5 & 138.0 & 138.0 & 136.6 \\
& NS & -1.78 & -1.12 & -0.45 & -0.43 & -0.52 & -0.45 & -0.45 & -0.45 \\
\hline \multirow{2}{*}{$2007-2009$} & $R$ & 0.58 & 0.60 & 0.61 & 0.62 & 0.59 & 0.62 & 0.64 & 0.64 \\
& RMSE & 69.3 & 62.9 & 57.6 & 55.7 & 84.7 & 82.7 & 82.7 & 82.9 \\
& NS & -0.45 & -0.17 & 0.06 & 0.08 & 0.14 & 0.18 & 0.19 & 0.18 \\
\hline
\end{tabular}

The above results indicate better performance of the modified model with the optimized RWU function compared with the optimized root distribution scheme for simulating sensible heat flux in the three years and for latent heat flux in 2007. This shows that the former had greater effects on the simulation of energy fluxes than the latter, and at the same time showed that the two parameterization schemes improved model performance more significantly in 2007 and 2009 than in 2008. In addition, RMSEs of latent heat fluxes for M1 were smaller than those for M2, and RMSEs of sensible heat fluxes for M1 were larger than those for M2 in 2008 and 2009, possibly caused by imbalance in energy balance closure in turbulent energy flux measurements [25]. Moreover, incorporating two optimization schemes into the CoLM markedly improved model simulations of both sensible and latent heat fluxes 
in 2009, which might be associated with the low precipitation in this growing season relative to the other years.

\section{Discussion}

Agricultural ecosystems are widespread in the world; they are severely and widely affected by human activities and have been shown to be an important reason for climate change [36]. Maize farmland ecosystems have intense human intervention relative to forests, grasslands and other ecosystems. Nevertheless, few explicit conclusions have been drawn with respect to applicability of land surface models over maize farmland ecosystems, and few studies on the RWU process have been conducted [26].

It is important to mention first that the root data used to calculate RD parameters derived from different locations and years and were not obtained in the field where our experiment was conducted. In general, the mutual matching of research data will be more cogent, but we think that a common feature still exists in maize with the difference of variety or planting area. In this study, the data was only used to provide a set of indicative parameters for the research objectives of evaluating qualitatively the distinction between root length density and root biomass data. In fact, the difference of calculated root distributions from two kinds of data is very obvious. So, we think that the existing data was basically able to satisfy the research demand.

Root distribution and RWU are important components of any RWU parameterization scheme and have been proven to be the key to improving simulation accuracy of land surface models with rational optimization $[16,26]$. The optimization for root distribution and RWU both increase model performance by improving the vertical distribution of SWC, but the mechanisms used to realize this and the magnitude of improvement in SWC differ. In addition, the roles of root distribution optimization vary because of the accumulated root fraction calculated based on RB and RLD. In this study, comparing root distribution parameters calculated with two types of data showed that the parameters calculated with RB were smaller than those calculated with RLD, and the simulations of SWC and energy fluxes were evidently improved when root distribution was optimized with measured RLD. Wu et al. [37] proposed that maize mainly absorbs water from depths of $20-40 \mathrm{~cm}$ after the late jointing stage and below $40 \mathrm{~cm}$ after the tasseling stage, assessed using a stable oxygen isotope system. In fact, the chief RWU depth after the jointing stage in Wu's study was very close to the $d_{50}$ calculated with RLD in the present study, implying that it is better to adapt RLD to calculate root distribution parameters compared with RB for improving model performance. The reason for improved model performance with the modified root distribution scheme was probably that topsoil SWC increased due to reduced water uptake with the increased depth of $d_{50}$, causing the simulated latent heat flux to increase and so mitigate its underestimation.

This research used the RWU function proposed by Zheng and Wang [4] to improve simulation accuracy of energy flux and achieved a satisfactory outcome, attributed to the role of the $W_{c}$ parameter in determining whether the primary cumulative root efficiency to satisfy maximum plant transpiration was reached. This optimization in the RWU function improved simulation of SWC at different soil depths, and increased simulation accuracies of energy fluxes to some extent. Additionally, both optimization schemes improved model performance during continuous non-precipitation days or in years with relatively less precipitation. The distribution of maize roots spreads toward deeper soil when suffering from drought stress after the jointing stage [17], further promoting the increase of simulated SWC in topsoil. Similarly, the difference between modified and default RWU functions was clear during dry periods [16]. Conversely, both optimization schemes barely improved simulation accuracies for energy flux during stages with high SWC or in years with abundant precipitation. Objectively, the role of improved RWU schemes should be limited by a threshold of SWC, and would then be very insensitive outside this range. In view of the limited effect below a certain level of SWC, improvement in model performance generated by simultaneously modifying root distribution and the RWU function was only reflected when maize growth reached a high water-consuming stage in the 
years with less precipitation. Most notably, simulation accuracy of sensible heat flux for certain days dropped after the optimization, which was possibly caused by the following aspects. Firstly, the energy imbalance for the observed data based on the eddy correlation system is unavoidable in any research site [26]. As a result, the observation error may be the source of the above-mentioned condition. Secondly, the other parameterization schemes in land surface models such as those related to runoff, infiltration, and transpiration [4] might be unseasonable, which keeps the default model in a balance state. However, the model performance decreases, on the contrary, when the balance is off with some parameter schemes being optimized, implying that the most important prerequisite in evaluating effectiveness of a parameterization scheme of certain physical processes is an accurate representation of associated processes.

Many studies aim to offer a universal RWU scheme to adapt to different water conditions and ecosystems, but none is available [26]. Various adaptive strategies for different water conditions are marked by diverse ecosystems. For instance, more efficient RWU will enable desert shrubs to accustom to drought [38], and hydraulic redistribution may play a critical role in maintaining transpiration within a rainforest ecosystem $[39,40]$. The conclusions of this study provide important support for adopting a set of effective RWU schemes in the CoLM model to simulate water and heat fluxes between the atmosphere and a rain-fed maize agroecosystem.

\section{Conclusions}

Based on 2007-2009 data in relation to energy flux and meteorological factors including air temperature, precipitation, air pressure, relative humidity and wind speed measured at Jinzhou maize agroecosystem research site, a comparative analysis was conducted to determine the optimal root distribution scheme. An optimized RWU function was introduced into the CoLM model. The effects of the optimized root distribution and RWU function on model performance were investigated. We came to the following conclusions:

(1) Compared with RB, RLD was used to calculate more actual root distribution parameters which more effectively reflected soil water availability, and which increased model performance in simulating water and heat fluxes between the atmosphere and underlying surface of a maize agroecosystem.

(2) The optimized root distribution parameters and the RWU function both improved simulation accuracies of SWC and sensible and latent heat fluxes in the years of little rainfall. Moreover, the combined roles of two optimization schemes in improving CoLM performance were significant during periods of continuous non-precipitation when maize has high demand for water to satisfy growth, but would be limited within a threshold of SWC and be inoperative outside this threshold.

Author Contributions: F.C. and Y.Z. conceived and designed the experiments; H.Z., X.Z. and Y.X. performed the experiments; N.M., H.M. and S.Z. analyzed the data; N.M. contributed analysis tools; F.C. wrote the paper.

Funding: This research was funded by the National Natural Science Foundation of China (41775110 and 31701313), Cultivation Plan for Youth Agricultural Science and Technology Innovative Talents of Liaoning Province (2015060), Liaoning province the key planning guidance program project (2017210001) and the sub subject of National Key Research and Development Plan Programs: scientific and technological innovation to increase the efficiency of food production (2018YFD0300300).

Acknowledgments: The authors are grateful to Li Rongping for providing the EC data.

Conflicts of Interest: The authors declare no conflict of interest.

\section{References}

1. Dickinson, R.E.; Shaikh, M.; Bryant, R.; Graumlich, L. Interactive canopies for a climate model. J. Clim. 1998, 11, 2823-2836. [CrossRef] 
2. Jobbágy, E.G.; Jackson, R.B. The vertical distribution of soil organic carbon and its relation to climate and vegetation. Ecol. Appl. 2000, 10, 423-436. [CrossRef]

3. Laio, F.; D'Odorico, P.; Ridolfi, L. An analytical model to relate the vertical root distribution to climate and soil properties. Geophys. Res. Lett. 2006, 33, L18401. [CrossRef]

4. Zheng, Z.; Wang, G.L. Modeling the dynamic root water uptake and its hydrological impact at the reserva Jaru site in Amazonia. J. Geophys. Res. 2007, 112, G04012. [CrossRef]

5. Maayar, M.; Oliver, S. Crop model validation and sensitivity to climate change scenarios. Clim. Res. 2009, 39, 47-59. [CrossRef]

6. Jackson, R.B.; Canadell, J.; Ehleringer, J.R.; Mooney, H.A.; Sala, O.E.; Schulze, E.D. A global analysis of root distributions for terrestrial biomes. Oecologia 1996, 108, 389-411. [CrossRef] [PubMed]

7. Bonan, G.B. A Land Surface Model (LSM Version 1.0) for Ecological, Hydrological, and Atmospheric Studies: Technical Description and User's Guide; NCAR Technical Note, NCAR/TN-417+STR; National Center for Atmospheric Research: Boulder, CO, USA, 1996; p. 150.

8. Snyder, P.K.; Delire, C.; Foley, J.A. Evaluating the influence of different vegetation biomes on the global climate. Clim. Dyn. 2004, 23, 279-302. [CrossRef]

9. Levis, S.; Bonan, G.B.; Vertenstein, M.; Oleson, K. The Community Land Models Dynamic Global Vegetation Model (CLM-DGVM): Technical Description and User's Guide; NCAR Technical Note, NCAR/TN-459+IA; National Center for Atmospheric Research: Boulder, CO, USA, 2004.

10. Baker, I.T.; Prihodko, L.; Denning, A.S.; Goulden, M.; Miller, S.; Da Rocha, H.R. Seasonal drought stress in the Amazon: Reconciling models and observations. J. Geophys. Res. 2008, 113. [CrossRef]

11. Zeng, X.B. Global vegetation root distribution for land modeling. Bull. Am. Meteorol. Soc. 2001, 2, 525-530. [CrossRef]

12. Schenk, H.J.; Jackson, R.B. The global biogeography of roots. Ecol. Monogr. 2002, 72, 311-328. [CrossRef]

13. Ji, D.Y.; Dai, Y.J. The Common Land Model (CoLM) Technical Guide; College of Global Change and Earth System Science, Beijing Normal University: Beijing, China, 2010; 60p. Available online: http:/ /globalchange.bnu. edu.cn/download/doc/CoLM/CoLM_Technical_Guide.pdf (accessed on 13 August 2018).

14. Cai, F.; Ming, H.Q.; Zhu, X.Y.; Mi, N.; Zhao, X.L.; Xie, Y.B.; Zhang, Y.S. Comparison on simulation methods of maize root distribution. Chin. J. Ecol. 2015, 34, 582-588.

15. Cai, F.; Ming, H.Q.; Mi, N.; Zhang, S.J.; Xie, Y.B.; Zhang, Y.S. Study of the effects of the root distribution on land-atmosphere water and heat flux exchanges based on CoLM: Corn field as a case. Acta Meteorol. Sin. 2015, 73, 566-576.

16. Jing, C.Q.; Li, L.H.; Chen, X.; Luo, G.P. Comparison of root water uptake functions to simulate surface energy fluxes within a deep-rooted desert shrub ecosystem. Hydrol. Process. 2013, 28, 5436-5449. [CrossRef]

17. Chen, P.S.; Cai, F.; Ji, R.P.; Xie, Y.B.; Shi, K.Q.; Yang, Y.; Zhang, H. Effects of drought stresses during different key growth periods on root growth of spring maize in Northeast China. Agric. Res. Arid Areas 2018, 35, 156-163.

18. Lai, C.T.; Katul, G. The dynamic role of root-water uptake in coupling potential and actual transpiration. Adv. Water Resour. 2000, 23, 427-439. [CrossRef]

19. Li, K.Y.; De Jong, R.; Coe, M.T.; Ramankutty, N. Root-water-uptake based upon a new water stress reduction and an asymptotic root distribution function. Earth Interact. 2006, 10. [CrossRef]

20. Saleska, S.R.; Miller, S.D.; Matross, D.M.; Goulden, M.L.; Wofsy, S.C.; Da Rocha, H.R.; de Camargo, P.B.; Crill, P.; Daube, B.C.; de Freitas, H.C. Carbon in amazon forests: Unexpected seasonal fluxes and disturbance induced losses. Science 2003, 302, 1554-1557. [CrossRef] [PubMed]

21. Li, L.H.; Wang, Y.P.; Yu, Q.; Pak, B.; Eamus, D.; Yan, J. Improving the responses of the Australian community land surface model (CABLE) to seasonal drought. J. Geophys. Res. 2012, 117, G04002. [CrossRef]

22. Molz, F.J. Models of water transport in the soil-plant system: A review. Water Resour. Res. 1981, 17, $1245-1260$. [CrossRef]

23. Chandra, S.P.O.; Rai, A.K. Nonlinear root-water uptake model. J. Irrig. Drain. Eng. 1996, 122, $198-202$.

24. Skaggs, T.H.; Van Genuchten, M.T.; Shouse, P.J.; Poss, J.A. Macroscopic approaches to root water uptake as a function of water and salinity stress. Agric. Water Manag. 2006, 86, 140-149. [CrossRef]

25. Li, L.H.; van der Tol, C.; Chen, X.; Jing, C.; Su, B.; Luo, G.; Tian, X. Representing the root water uptake process in the Common Land Model for better simulating the energy and water vapour fluxes in a Central Asian desert ecosystem. J. Hydrol. 2013, 502, 145-155. [CrossRef] 
26. Cai, F.; Ming, H.Q.; Mi, N.; Xie, Y.B.; Zhang, Y.S. Comparison of Effects of Root Water Uptake Functions on Surface Water and Heat Fluxes Simulations within Corn Farmland Ecosystem over Northeast China. J. Irrig. Drain. Eng. 2017, 143, 04017074. [CrossRef]

27. Wang, Y.P.; Law, R.M.; Pak, B. A global model of carbon, nitrogen and phosphorus cycles for the terrestrial biosphere. Biogeosciences 2010, 7, 2261-2282. [CrossRef]

28. Choi, M.; Lee, S.O.; Kwon, H. Understanding of the Common land model performance for water and energy fluxes in a farmland during the growing season in Korea. Hydrol. Process. 2010, 24, 1063-1071. [CrossRef]

29. Li, L.H.; Vuichard, N.; Viovy, N.; Ciais, P.; Wang, T.; Ceschia, E.; Jans, W.; Wattenbach, M.; Béziat, P.; Gruenwald, T.; et al. Importance of crop varieties and management practices: Evaluation of a process-based model for simulating $\mathrm{CO}_{2}$ and $\mathrm{H}_{2} \mathrm{O}$ fluxes at five European maize (Zea mays L.) sites. Biogeosciences 2011, 8, 1721-1736. [CrossRef]

30. Cai, F.; Zhou, G.S.; Ming, H.Q.; Li, R.P.; Zhang, G.; He, Q.J.; Duan, J.Q. A simulative study of effects of dynamic parameterization of surface albedo on land-atmosphere flux exchanges: A case study of rainfed maize field in northeast China. Acta Meteorol. Sin. 2012, 70, 1149-1164.

31. Cai, F.; Ming, H.Q.; Ji, R.P.; Feng, R.; Mi, N.; Zhao, X.L.; Zhang, Y.S. Effects of maize canopy radiative transfer parameters optimization on simulating land-atmosphere flux exchanges. Adv. Earth Sci. 2014, 29, 598-607.

32. Guan, J.H. Study on Characteristies of Root System Growth and Relationship between Root and Upland Parts of Maize; Inner Mongolia Agricultural University: Inner Mongolia, China, 2007.

33. Liao, R.W.; Liu, J.M.; An, S.Q.; Niu, J.L.; Liang, H.; Ren, S.X.; Le, Z.Y.; Cao, Y.J.; Li, W.J. Monitor of corn root growth in soil based on minirhizotron technique. Trans. CSAE 2010, 26, 156-161.

34. Falge, E.; Baldocchi, D.D.; Olson, R. Gap-filling strategies for long-term energy flux datasets. Agric. For. Meteorol. 2001, 107, 71-77. [CrossRef]

35. Moriasi, D.N.; Arnold, J.G.; Van Liew, M.W. Model Evaluation Guidelines for Systematic Quantification of Accuracy in Watershed Simulations. Trans. ASABE 2007, 50, 885-900. [CrossRef]

36. Stocker, T.F.; Qin, D.; Plattner, G.K.; Tignor, M.; Allen, S.K.; Boschung, J.; Nauels, A.; Xia, Y.; Bex, V.; Midgley, P.M. IPCC (2013) Climate Change. The Physical Science Basis. Contribution of Working Group I to the Fifth Assessment Report of the Intergovernmental Panel on Climate Change; Cambridge University Press: Cambridge, UK; New York, NY, USA, 2013; p. 1535.

37. Wu, Y.J.; Du, T.S.; Li, F.S.; Li, S.E.; Ding, R.S.; Tong, L. Quantification of maize water uptake from different layers and rootzones under alternate furrow irrigation using stable oxygen isotope. Agric. Water Manag. 2016, 168, 35-44. [CrossRef]

38. Xu, H.; Li, Y.; Xu, G.Q.; Zou, T. Ecophysiological response and morphological adjustment of two Central Asian desert shrubs towards variation in summer precipitation. Plant Cell Environ. 2007, 30, 399-409. [CrossRef] [PubMed]

39. Oliveira, R.S.; Dawson, T.E.; Burgess, S.S.O.; Nepstad, D.C. Hydraulic redistribution in three Amazonian trees. Oecologia 2005, 145, 354-363. [CrossRef] [PubMed]

40. Lee, J.E.; Oliveira, R.S.; Dawson, T.E.; Fung, L. Root functioning modifies seasonal climate. Proc. Natl. Acad. Sci. USA 2005, 102, 17576-17581. [CrossRef] [PubMed]

(C) 2018 by the authors. Licensee MDPI, Basel, Switzerland. This article is an open access article distributed under the terms and conditions of the Creative Commons Attribution (CC BY) license (http://creativecommons.org/licenses/by/4.0/). 